Relato de experiência

\title{
GeoGebra grupos e objetos de aprendizagem: um recurso para exploração do raciocínio covariacional em tempos de aulas não presenciais
}

\section{GeoGebra groups and learning objects: a resource for exploring covariational reasoning for remote classes}

\author{
GeoGebra grupos y objetos de aprendizaje: un recurso para la exploración del \\ razonamiento covariacional durante las clases no presenciales
}

\author{
Jeferson Moizés Lima ${ }^{1}$ \\ [0000-0002-6456-8645] \\ Ivanete Zuchi Siple ${ }^{2}$ \\ [0000-0002-8640-1336]
}

\begin{abstract}
Resumo
Este relato apresenta a experiência vivenciada por um professor de matemática do Ensino Médio na transição das aulas presenciais para remotas em tempos da pandemia da COVID-19. Nele, será descrita uma prática sobre o ensino de funções, na perspectiva do raciocínio covariacional em uma turma de alunos do primeiro ano do Ensino Médio, detalhando a utilização de objetos de aprendizagem construídos no GeoGebra e da ferramenta Grupos, uma sala de aula virtual disponibilizada pelo GeoGebra on-line, no desenvolvimento das atividades. Os objetos de aprendizagem foram construídos com foco no desenvolvimento do raciocínio covariacional e nos diferentes registros de representação de um mesmo objeto matemático. Essa ênfase foi dada, pois esse tipo raciocínio, pouco desenvolvido nos alunos e importante para o estudo de funções, é utilizado para interpretação, representação e justificativa de como valores de duas quantidades (magnitudes), em uma determinada situação, variam simultaneamente e um em relação ao outro. As atividades desenvolvidas propiciaram aos alunos a exploração do conceito de função por meio de diferentes representações de situaçõesproblemas, tais como a visualização da situação-problema, a linguagem natural utilizada por eles em seus argumentos para justificar escolhas e as representações gráficas realizadas.
\end{abstract}

Palavras-chave: Tecnologias Digitais. GeoGebra. Raciocínio Covariacional.

\begin{abstract}
This report presents a practice of a teacher of high school mathematics in the transition from classroom to remote classes in times of the COVID-19 pandemic. A practice on teaching functions will be described, from the perspective of covariational reasoning in a class of first year high school students, detailing the use of learning objects built in GeoGebra and the Groups tool, a virtual classroom made available by GeoGebra online. The learning objects were built with a focus on the development of covariational reasoning and the different registers of representation of the same
\end{abstract}

\footnotetext{
1 jefemat@hotmail.com, mestre em Ensino de Ciências, Matemática e Tecnologias, doutorando em Educação no Programa de Pós-Graduação (FAED) da Universidade do Estado de Santa Catarina (UDESC), Florianópolis/Santa Catarina/Brasil.

2 ivanete.siple@udesc.br, doutora em Engenharia de Produção, professora do Programa de Pós-Graduação em Ensino de Ciências, Matemática e Tecnologias do Departamento de Matemática - Universidade do Estado de Santa Catarina (UDESC), Joinville/Santa Catarina/Brasil.
} 
mathematical object. This emphasis was given because this type of reasoning, poorly developed in students and important for the study of functions, is used for interpretation, representation and justification of how values of two quantities (magnitudes), in a given situation, vary simultaneously and one in relation to the other. The activities developed enabled students to explore the concept of the function through different representations of problem situations, such as visualizing the problem situation, the natural language used by them in their arguments to justify choices and the graphic representations made.

Keywords: Digital Technologies. GeoGebra. Covariational reasoning.

\section{Resumen}

Este informe presenta la experiencia vivida por un profesor de matemáticas de la Enseñanza Media en la transición de clases presenciales para remotas durante la pandemia de COVID-19. En este texto, se describirá una práctica sobre la enseñanza de funciones, desde la perspectiva del razonamiento covariacional en una clase de estudiantes de primer año de la Enseñanza Media, detallando el uso de objetos de aprendizaje construidos en GeoGebra y la herramienta Grupos, un salón de clases virtual puesto a disposición por GeoGebra online, en el desarrollo de actividades. Los objetos de aprendizaje se construyeron con un enfoque en el desarrollo del razonamiento covariacional y los diferentes registros de representación de un mismo objeto matemático. Este énfasis se dio, porque este tipo de razonamiento, poco desarrollado en los estudiantes e importante para el estudio de funciones, se utiliza para la interpretación, representación y justificación de cómo los valores de dos cantidades (magnitudes), en una situación dada, varían simultáneamente y un en relación al otro. Las actividades desarrolladas permitieron a los estudiantes explorar el concepto de función a través de diferentes representaciones de situaciones problemáticas, como la visualización de la situación problema, el lenguaje natural que utilizan en sus argumentos para justificar sus elecciones y las representaciones gráficas realizadas.

Palabras claves: Tecnologías Digitales. GeoGebra. Razonamiento Covariacional.

\section{Introdução}

No dia 17 de março de 2020, por meio da Portaria no 343, o Ministério da Educação (MEC) se manifestou sobre a substituição das aulas presenciais por aulas em meios digitais, enquanto perdurasse a situação de pandemia da COVID-19. Nesse momento, foi necessário que os educadores potencializassem o uso de tecnologias digitais como alternativa estratégica pedagógica para a realização das aulas remotas. Diante desse cenário, compartilharemos a experiência que o primeiro autor, professor de matemática da Educação Básica, teve em uma turma de primeiro ano do Ensino Médio, da rede privada, no estado de Santa Catarina, com o ensino e aprendizagem de matemática, adaptando e utilizando recursos digitais que já se faziam presentes em sua prática pedagógica, bem como aprendendo e familiarizando-se com novas tecnologias que o auxiliaram nesta transição.

Com a transição das aulas presenciais para remotas, a integração das tecnologias digitais, algumas das quais já estavam presentes na nossa prática docente, tornou-se essencial para o desenvolvimento das atividades e a interação entre alunos e professor. A pesquisa sobre tecnologias digitais para o ensino da matemática, a qual resultou em um produto educacional sobre o ensino de funções desenvolvido na plataforma GeoGebra e aplicado presencialmente (LIMA, 2019a), foi essencial para a incorporação deste material às novas práticas, para a expansão das atividades propostas e para a aprendizagem de novas tecnologias necessárias para continuidade dos processos de ensino e aprendizagem nesse 
novo contexto. Neste relato, apresentaremos uma prática realizada com o uso de objetos de aprendizagem para o ensino de funções na perspectiva da covariação e as potencialidades do GeoGebra neste processo.

O entendimento do conceito de função no Ensino Médio vai além da identificação de funções por meio de gráficos, relação entre conjuntos ou expressões algébricas. Ao estudar o conceito de função, é essencial que o aluno compreenda que este é um processo dinâmico de covariação, ou seja, que é a variação dos valores de duas quantidades que ocorre simultaneamente (THOMPSON; CARLSON, 2017).

Para facilitar essa compreensão é importante que o professor disponibilize aos estudantes, atividades que os incentivem a analisar informações envolvendo variação entre grandezas e que seja possível converter um registro matemático para outro. Além do mais, para compreensão de conceitos matemáticos "as diversas representações semióticas de um objeto matemático são absolutamente necessárias" (DUVAL, 2012, p.268).

O GeoGebra, software de matemática dinâmica, reúne recursos de geometria, de álgebra, de folhas de cálculo, de gráficos, de estatística e de cálculo, em um layout relativamente simples de manusear, os quais podem potencializar o ensino da matemática, em particular no ensino de funções na perspectiva da covariação. O software oportuniza, além de diferentes formas de representações de um objeto matemático, conectadas de maneira dinâmica, o acesso em dispositivos eletrônicos que permitem ao aluno estar conectado, online ou off-line, na palma da mão. Outro fator importante para a utilização do GeoGebra é a possibilidade de o professor, em seu perfil, criar um grupo, espécie de sala de aula virtual, sendo capaz de disponibilizar atividades que possibilitem ao aluno investigar, avaliar, prever e validar suas hipóteses, auxiliando-o na construção de significados. Além disso, é possível incentivar a cooperação na realização das atividades entre os participantes do grupo e proporcionar feedback para as resoluções. Vale informar que o aluno é comunicado por email no momento em que o professor disponibiliza tanto a atividade quanto o feedback, tendo a oportunidade de refazer a atividade, caso seja necessário.

Além da utilização dos objetos de aprendizagem e da ferramenta Grupos do GeoGebra, foram utilizadas outras ferramentas tecnológicas para o desenvolvimento da prática. No encontro virtual síncrono com os alunos foi utilizado a Webex ${ }^{3}$, plataforma de videoconferência adotada pela escola onde o professor atua. Essa plataforma digital foi introduzida logo que as aulas remotas foram anunciadas, possibilitando uma interação síncrona entre o professor e os alunos durante as aulas. Além disso, o professor incorporou ao seu notebook uma mesa digitalizadora, um recurso que facilita o trabalho do professor de matemática no que diz respeito à escrita de notação matemática e desenhos gráficos, em tempo real. Essas duas tecnologias, que não eram utilizadas nas aulas presenciais, foram incorporadas à prática do professor no momento das aulas remotas.

Associando os conhecimentos sobre o GeoGebra Grupos e objetos dinâmicos de aprendizagem na perspectiva da covariação (LIMA, 2019b) e a necessidade do momento, foi possível desenvolver novas atividades. Para a proposição das atividades, foi considerado o trabalho de pesquisadores em Educação Matemática, como Thompson e Carlson (2017), cujas investigações mostram que, para o ensino e aprendizagem de funções, há a necessidade de um desenvolvimento que inclua uma concepção de função como covariação; e Raymond

\footnotetext{
${ }^{3}$ Disponível em: <https://www.webex.com/pt/index.html>. Acesso em: 07 jul. 2020.
} 
Duval (2012), que postula que o ponto estratégico para a compreensão da matemática é a distinção entre um objeto e sua representação.

\subsection{0 ensino de função na perspectiva da covariação}

Carlson (2002, p. 63, tradução nossa) afirma que "os alunos têm dificuldade em traduzir um registro de representação de função para outra", e que "os materiais curriculares não estão amplamente disponíveis para promover o desenvolvimento dessas habilidades". As atividades descritas neste relato apresentam como objetivo contribuir nessa problemática apontada pela autora, contemplando atividades sobre exploração do raciocínio covariacional e de diferentes registros de representação dos objetos matemáticos, uma vez que "é essencial, na atividade matemática, poder mobilizar muitos registros de representação semiótica (figuras, gráficos, escrituras simbólicas, língua natural) no decorrer de um mesmo passo, poder escolher um registro no lugar de outro" (DUVAL, 2012, p.270).

Nessa perspectiva, o que se propõe é que o estudante desenvolva um raciocínio chamado de raciocínio covariacional, que de acordo com Carlson et al. (2002, p.354), "referese às atividades cognitivas envolvidas na coordenação de duas quantidades variando, levando em consideração a forma em que elas variam em relação uma à outra". Carlson (2002) ainda considera que este raciocínio é importante para interpretar e representar funções que variam dinamicamente. Exemplos de raciocínio covariacional inclui ações mentais de visualizar uma variação dinâmica no eixo $x$, ao mesmo tempo em que se forma uma imagem de magnitude da variação da altura do gráfico, tal como na situação de encher uma garrafa com água que "envolve pensar sobre a quantia de variação de água na garrafa ao mesmo tempo que se constrói uma imagem da magnitude da variação da altura da água na garrafa" (CARLSON, 2002, p.65, tradução nossa).

Esse é outro ponto importante sobre o raciocínio covariacional, a saber, as ações mentais que uma pessoa produz em relação a uma tarefa específica. Carlson et al. (2002) apresentam um quadro conceitual fornecendo uma descrição das cinco ações mentais, apresentadas no Quadro 1, sobre o raciocínio covariacional e os comportamentos associados.

Esse marco teórico utiliza situações envolvendo representações gráficas para descrever os diferentes níveis de raciocínio covariacional.

Quadro 1: Ações mentais da estrutura conceitual para covariação

\begin{tabular}{|c|l|l|l|}
\hline Ação Mental & Descrição da ação mental & \multicolumn{2}{|c|}{ Comportamentos } \\
\hline AM1 & $\begin{array}{l}\text { Coordenação do valor de } \\
\text { uma variável com a } \\
\text { variação da outra. }\end{array}$ & $\begin{array}{l}\text { Designação dos eixos com indicações verbais de } \\
\text { coordenação das duas variáveis (exemplo: } y \text { varia } \\
\text { com as variações em } x \text { ) }\end{array}$ \\
\hline $\mathrm{AM}^{4}$ & $\begin{array}{l}\text { Coordenação da direção da } \\
\text { variação de uma variável } \\
\text { com a variação na outra } \\
\text { variável. }\end{array}$ & $\begin{array}{l}\text { Construção de uma reta crescente ou } \\
\text { decrescente. } \\
\text { Verbalização da compreensão da direção da } \\
\text { variação da saída, enquanto é considerada a } \\
\text { variação na entrada. }\end{array}$ \\
\hline $\mathrm{AM} 3$ & $\begin{array}{l}\text { Coordenação da } \\
\text { "quantidade de variação" }\end{array}$ & $\begin{array}{l}\text { Marcação de pontos/construção de retas } \\
\text { secantes. }\end{array}$ \\
\hline
\end{tabular}

\footnotetext{
${ }^{4}$ A ação mental 2 (AM2) foi adaptada para construção de uma reta (direção) crescente ou decrescente.
} 


\begin{tabular}{|c|c|c|}
\hline & $\begin{array}{l}\text { de uma variável com a } \\
\text { variação da outra. }\end{array}$ & $\begin{array}{l}\text { Verbalização da compreensão da direção da } \\
\text { variação da saída, enquanto é considerada a } \\
\text { variação da entrada. }\end{array}$ \\
\hline AM4 & $\begin{array}{l}\text { Coordenação da taxa de } \\
\text { variação média da função } \\
\text { com os incrementos } \\
\text { constantes de variação na } \\
\text { variável de entrada. }\end{array}$ & $\begin{array}{l}\text { Construção de retas secantes contíguas para o } \\
\text { domínio. } \\
\text { Verbalização da compreensão da taxa de variação } \\
\text { na saída (comparada com a da entrada), enquanto } \\
\text { são considerados os incrementos constantes na } \\
\text { entrada. }\end{array}$ \\
\hline AM5 & $\begin{array}{l}\text { Coordenação da taxa de } \\
\text { variação instantânea da } \\
\text { função com a variação } \\
\text { contínua na variável } \\
\text { independente para todo o } \\
\text { domínio da função. }\end{array}$ & $\begin{array}{l}\text { Construção de uma curva suave com indicações } \\
\text { claras de mudança de concavidades. } \\
\text { Verbalização da compreensão da variação } \\
\text { instantânea na taxa de variação para todo o } \\
\text { domínio da função (direção de concavidades e } \\
\text { pontos de inflexão estão corretos). }\end{array}$ \\
\hline
\end{tabular}

Fonte: Carlson et al. (2002, p.357, tradução nossa)

\section{Metodologia}

Neste trabalho visamos compartilhar uma experiência da transição das aulas presenciais para remotas, expondo uma prática no Ensino Médio sobre o ensino de funções na perspectiva da covariação.

A experiência ocorreu em uma turma de 28 alunos matriculados no primeiro ano do Ensino Médio da rede privada, no estado de Santa Catarina, em dois formatos: síncrono $^{5}$ pela plataforma de videoconferência utilizada pela escola - Webex - e assíncrono ${ }^{6}$, ou seja, professor e alunos trabalham separados na plataforma GeoGebra Grupos.

Na proposição das atividades, as quais abordam o conceito de função sob a ótica de variação, adaptamos algumas tarefas do produto educacional do autor 1 (LIMA, 2019a) e que já eram utilizadas em aulas presenciais. Tais atividades, no GeoGebra, podem combinar diferentes elementos, tais como: textos, imagens, links, questões abertas ou de múltipla escolha e applets no layout de apresentação, sendo disponibilizadas aos alunos por meio do recurso "Grupos", oferecido pela plataforma do GeoGebra on-line. O GeoGebra Grupos” é uma ferramenta a partir da qual o professor pode gerenciar e compartilhar as atividades com os membros de um grupo (no nosso caso, os alunos). É possível acompanhar o desenvolvimento das atividades realizadas, dando feedback para as tarefas efetuadas, gerenciar tarefas para outros membros do grupo (por exemplo, alunos) e acompanhar o trabalho dos membros. Aluno e professor podem se comunicar por meio de posts com comentários.

Inicialmente foi apresentada a ferramenta Grupos aos alunos, de forma síncrona, com o intuito de familiarizar os alunos com tal recurso. Após essa explanação, foi compartilhado com os alunos o código de acesso ao grupo. Neste instante, os estudantes realizaram o

\footnotetext{
${ }^{5}$ Interação entre o professor e os alunos acontece em tempo real, uma vez que todos precisam estar ao mesmo tempo e no mesmo ambiente virtual.

${ }^{6}$ Interação entre o professor e os alunos não ocorre ao mesmo tempo, a comunicação ocorre, por exemplo, via e-mail ou fóruns.

${ }^{7}$ Disponível em: <https://www.geogebra.org/m/rQrbooeq>. Acesso em: 07 de jul. de 2020.
} 
cadastro no GeoGebra, por meio de um e-mail pessoal, inseriram o código do grupo que foi disponibilizado, obtendo acesso às atividades propostas.

Durante as aulas virtuais, realizadas de forma síncrona, professor e alunos utilizaram câmera e microfone do aparelho digital (notebook, computador de mesa, tablet, smartphone) para comunicação. A câmera era deixada ligada na maior parte das vezes pelos alunos e o microfone só era acionado quando desejassem falar ou lhes era feito um questionamento. Além desses recursos, o professor utilizou uma mesa digitalizadora para escrever e desenhar quando foi necessário explicar determinada situação e corrigir as atividades com os alunos. É importante destacar que, antes da correção feita de forma síncrona, o professor realizou correção e feedback das atividades de forma assíncrona, oferecendo novas oportunidades de aprendizagem aos alunos.

Esse momento de aula assíncrona foi realizado em tempos e espaços diferentes, pois cada aluno pôde escolher quando desejava responder ao professor. O diálogo e os registros entre professor e alunos se deram de forma on-line com posts de comentários, pela ferramenta Grupos do GeoGebra. Cada post feito, tanto pelos alunos quanto pelo professor, gerava um e-mail de aviso enviado automaticamente. Assim, o professor forneceu e recebeu feedback dos alunos sobre a realização das tarefas para aqueles que não haviam respondido satisfatoriamente durante as aulas síncronas.

Para análise de dados das atividades propostas foram utilizados os registros de resoluções desenvolvidos pelos alunos e armazenadas na ferramenta Grupos do Geogebra online, bem como as observações feitas durante a aplicação, utilizando-se o recurso diário de bordo, a saber, anotações relevantes para a aplicação (quantidade de alunos presentes, dúvidas e discussões geradas pelos alunos, entre outras) e o suporte teórico com abordagem na teoria de variação de Thompson e Carlson (2017) e a representação semiótica à luz de Raymond Duval (2012). Os alunos foram codificados pela letra " $A$ " seguida de um número A1, A2, A3 -, a fim de não comprometer a sua identidade.

\section{Contexto da experiência}

Nesta seção apresentaremos o contexto da prática, descrevendo as atividades e seus objetivos, números de alunos presentes em cada aula e o tipo de aula.

Com base nas investigações de pesquisadores da Educação Matemática como, por exemplo, a teoria de variação de Thompson e Carlson (2017) e a representação semiótica à luz de Raymond Duval (2012), desenvolvemos quatro atividades envolvendo gráficos (Quadro 2). O intuito delas é promover o raciocínio covariacional e são "destinadas a proporcionar aos alunos oportunidades de conceber mudanças nos atributos antes de determinar números para quantidades de mudança" (JOHNSON et al., 2018, p.1225, tradução nossa). Entendemos com isso, como esclarece Moore e Thompson (2015) que "os alunos pensando sobre os gráficos estão posicionados para refletir sobre o seu raciocínio formando abstrações e generalizações deles" (MOORE e THOMPSON, 2015, p.787, tradução nossa).

Duas das atividades desenvolvidas tinham o objetivo de levar o aluno à análise de informações envolvendo a variação de grandezas como recurso para construção de argumentação, pois a atividade não oferecia valores numéricos e sim uma situação-problema a partir da qual o aluno deveria refletir sobre qual dos gráficos apresentados melhor descreveria o comportamento da situação proposta, justificando sua escolha em linguagem natural. As outras atividades tinham o objetivo de promover, além da análise das informações 
envolvendo a variação de grandezas, a representação gráfica da situação por meio de um esboço feito à mão livre com o recurso "Caneta" do GeoGebra.

Quadro 2: Dados sobre aplicação das atividades

\begin{tabular}{|c|c|c|c|c|}
\hline ATIVIDADE & $\begin{array}{c}\text { DATA DE } \\
\text { APLICAÇÃO }\end{array}$ & $\begin{array}{c}\mathbf{N}^{\circ} \text { DE } \\
\text { ALUNOS }\end{array}$ & $\begin{array}{c}\mathbf{N}^{\circ} \text { DE } \\
\text { AULAS }^{8}\end{array}$ & TIPO DE AULA \\
\hline Cadastro no GeoGebra on-line & $04 / 06 / 20$ & 28 & 1 & Síncrona \\
\hline Cone Invertido - Cl & $04 / 06 / 20$ & 28 & 1 & Síncrona \\
\hline $\begin{array}{c}\text { Clube do Livro - CL } \\
\text { Cone Invertido e Clube do } \\
\text { Livro }\end{array}$ & $\begin{array}{c}04 / 06 / 20 \\
17 / 06 / 20\end{array}$ & 28 & 1 & Síncrona \\
\hline Ralo Cilíndrico - RC & $18 / 06 / 20$ & 27 & 1 & Síncrona \\
\hline Ralo Cilíndrico & $\begin{array}{c}18 / 06 / 20 a \\
24 / 06 / 20\end{array}$ & 27 & - & Assíncrona \\
\hline Ampulheta - A & $25 / 06 / 20$ & 27 & 1 & Síncrona \\
\hline Ampulheta & $25 / 06 / 20 a$ & 27 & - & Assíncrona \\
& $01 / 07 / 20$ & & & \\
\hline
\end{tabular}

Fonte: Dados dos autores, 2020.

Inicialmente, antes da aplicação das atividades de maneira síncrona pelo Webex, o professor realizou uma explanação sobre o funcionamento da ferramenta Grupos na plataforma do GeoGebra para os 28 alunos presentes na aula. Após esse momento, os alunos fizeram o cadastro no GeoGebra on-line com o e-mail pessoal e ingressaram, com um código liberado pelo professor, no grupo criado para a turma. Essa aula teve por objetivo além do cadastro, a familiarização dos estudantes com a ferramenta para que dificuldades técnicas de utilização dos comandos não interferissem na aprendizagem dos alunos.

As duas atividades disponibilizadas nesta aula foram "Cone Invertido $(\mathbf{C l})$ "9 e "Clube do Livro (CL)"10. Elas foram construídas com o intuito de que, a partir da leitura de uma determinada situação, o aluno conseguisse identificar a variação simultânea de grandezas envolvidas. $\mathrm{Na}$ atividade $\mathrm{Cl}$, adaptamos uma situação-problema do vestibular da UFRGS ${ }^{11}$ (2016), a qual apresentava um cone com vértice para baixo, propondo ao aluno identificar qual gráfico descreveria o comportamento do nível da água em relação ao tempo, no momento em que esse cone fosse sendo completado com água. Queria-se saber, portanto, o comportamento gráfico da altura $y$ em função do tempo $x$, considerando uma vazão constante. A Figura 1 apresenta o layout da atividade Cone Invertido.

\footnotetext{
${ }^{8}$ Uma aula corresponde a 45 minutos.

${ }^{9}$ Disponível em: < https://www.geogebra.org/m/rbkcpyef>. Acesso em: 28 de ago. de 2021.

${ }^{10}$ Disponível em: <https://www.geogebra.org/m/sdpg5d7x $>$. Acesso em: 28 de ago. de 2021.

${ }^{11}$ Universidade Federal do Rio Grande do Sul.
} 
Já para a atividade $\mathbf{C L}$, propomos uma situação-problema adaptada do Insper ${ }^{12}$ (2014), sobre o comportamento da leitura de páginas de um livro em função do tempo. $O$ aluno teria que indicar qual seria o comportamento gráfico do número de páginas lida $N$ em função do tempo $t$. Após esse processo de identificação, que ocorre durante a leitura da situaçãoproblema, o aluno deveria escolher o gráfico que se adequaria melhor ao seu raciocínio e justificar, em linguagem natural, sua escolha.

Figura 1: Layout da atividade Cone Invertido no GeoGebra

Objetivos:

- Identificar graficamente a relação de dependência entre grandezas;

- Analisar informações envolvendo a variação de grandezas como recurso para construção de argumentação.

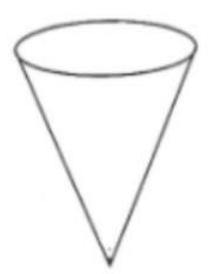

Analise qual dos gráficos abaixo melhor representa a altura y que a água atinge, no recipiente, em função do tempo $\mathrm{x}$. Justifique sua escolha no espaço abaixo dos gráficos.
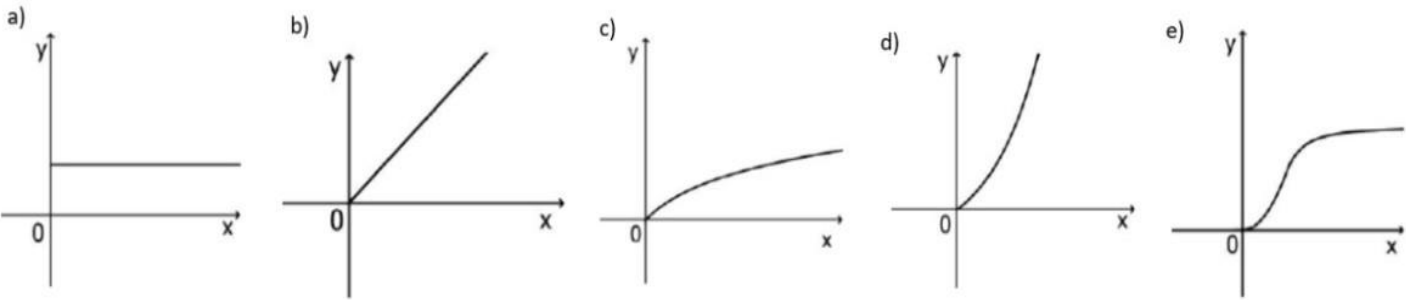

Qual dos gráficos foi escolhido? Justifique. (A justificativa é o momento em que você poderá convencer-me a concordar ou não com tua escolha; por isso lembre-se de escrever bons argumentos).

Fonte: Acervo dos Autores, 2020.

Para realizar as duas tarefas, os alunos despenderam uma aula. Enquanto a concluíam, o professor ficou disponível, de forma on-line, para responder a eventuais dúvidas. Entretanto, surgiram somente alguns comentários como, por exemplo, "professor, não sei se estou fazendo certo". É possível que este comportamento dos alunos tenha acontecido por insegurança, visto que o professor só tem acesso as resoluções após o envio das mesmas. 0 tempo de conclusão da atividade não foi o mesmo para cada aluno. Aqueles que concluíam perguntavam se o envio da atividade havia obtido sucesso. Como a plataforma Grupos permite gerenciar o status ${ }^{13}$ da atividade, foi possível ir informando a entrada das mesmas. Dos 28 alunos, quatro não conseguiram concluir no tempo programado, questionando se poderiam terminar como "tarefa de casa". Nesse momento foi informado que sim.

Checando as atividades entregues, o professor passou para o momento de aula assíncrona, ou seja, o professor faz as correções em um horário fora daquele em que estaria

\footnotetext{
12 Instituição de Ensino Superior Brasileira.

13 Para acompanhar o andamento de atividades, há ícones de status, os quais pode-se utilizar como filtro, que informam se o aluno iniciou ou não a atividade e se a concluiu.
} 
em sala de aula. Nesta etapa, o professor fez a correção das atividades e forneceu um feedback das resoluções para cada aluno individualmente, uma facilidade que o GeoGebra Grupos oferece por meio dos posts, a saber, espaço em que é permitido escrever um comentário, sendo gerado automaticamente um e-mail informando ao aluno ou ao professor sobre essa ocorrência. Após os alunos terem recebido esse feedback, aqueles que não responderam satisfatoriamente a uma ou duas atividades, tiveram nova oportunidade de aprendizagem, pois o professor não escreveu diretamente que a resposta estava errada, mas sim, forneceu questionamentos que instigavam o aluno a repensar sua argumentação inicial e responder ao post deixado pelo professor. A Figura 2 apresenta a resolução inicial escrita pelo aluno $A 1$, o feedback do professor e a contrarresposta do aluno.

Figura 2: Resolução escrita pelo aluno A1 e o feedback do professor

Qual dos gráficos foi escolhido? Justifique. (A justificativa é o momento em que você poderá convencer-me a concordar ou não com tua escolha; por isso, lembre-se de escrever bons argumentos).

\footnotetext{
A Acredito que a resposta correta seja a letra D, pois a alternativa representa melhor como a água A iria subir fazendo isso de forma vertical tendo um deslize na subida por conta da parte superior do $f_{\mathrm{x}}$ cone ( conforme a água sobe o volume fica maior)
}

\section{Pensando nessas perguntas acredito então que a alternativa correta seria a letra $C$, pois conforme o cone vai enchendo de água o tempo necessário para que o mesmo seja totalmente preenchido vai aumentando , ou seja, no início a água enche rapidamente e no final fica mais lento.}

Fonte: Acervo dos Autores, 2020.

Decorrida uma semana da aplicação das duas atividades $\mathbf{C l}$ e $\mathbf{C L}$, e após os alunos terem recebido e respondido ao feedback do professor de forma assíncrona nesse período, realizamos a terceira aula. Desta vez, os alunos foram convidados a socializar com o grupo de forma oral o raciocínio e os argumentos que haviam utilizado naquelas atividades, o que se mostrou como um momento enriquecedor de discussões e aprendizagem. Após a discussão e formalização dos argumentos para registros no caderno que utilizam para a disciplina de Matemática, o professor disponibilizou a terceira atividade, e solicitou que a realização desta fosse até o final da aula. Esta folha de trabalho, foi denominada "Ralo Cilíndrico (RC)"14, conforme o layout apresentado na Figura 3.

Na construção desse objeto de aprendizagem RC, disponibilizamos um applet dinâmico que simulava a situação-problema proposta, ou seja, a situação informava ao aluno que havia um tanque no formato cilíndrico cheio de água. Este cilindro possuía um ralo que foi aberto, liberando essa água de forma constante.

Para que o aluno pudesse visualizar essa cena de maneira dinâmica, criamos três botões de comando nesse applet: Iniciar, Parar e Reiniciar (Figura 4-A). No corpo do texto,

\footnotetext{
${ }^{14}$ Disponível em: <https://www.geogebra.org/m/usrt37gd > . Acesso em: 28 de ago. de 2021.
} 
foi solicitado que o aluno clicasse no botão "Iniciar", nesse momento, ele teria condições de perceber, que o cilindro cheio de água (deixamos em azul) e com vazão constante seria esvaziado à medida que o tempo fosse passando (Figura 4-B). Também criamos um controle deslizante, situado na "janela de visualização 2" (Figura 4-C), para que ele pudesse arrastar e verificar o cilindro sendo esvaziado, o que representa uma opção para auxiliar na validação de suas hipóteses. Após terem feito esta observação, deveriam representar graficamente o comportamento dessa situação-problema, no espaço chamado de "janela de visualização 2", localizado no lado direito da simulação (Figura 4 - D). Para isso, deixamos disponível a ferramenta "Caneta" (Figura 4 - E), a qual seria utilizada por meio de mouse ou do dedo, a depender se em uso de computador de mesa/notebook ou tablet/smartphone. Tendo construído o gráfico, também deveria justificar sua construção por meio da linguagem natural no espaço localizado abaixo da simulação (Figura $4-F$ ). Neste momento, o aluno deveria apresentar os argumentos que fundamentaram sua construção.

Figura 3: Layout do objeto de aprendizagem no GeoGebra
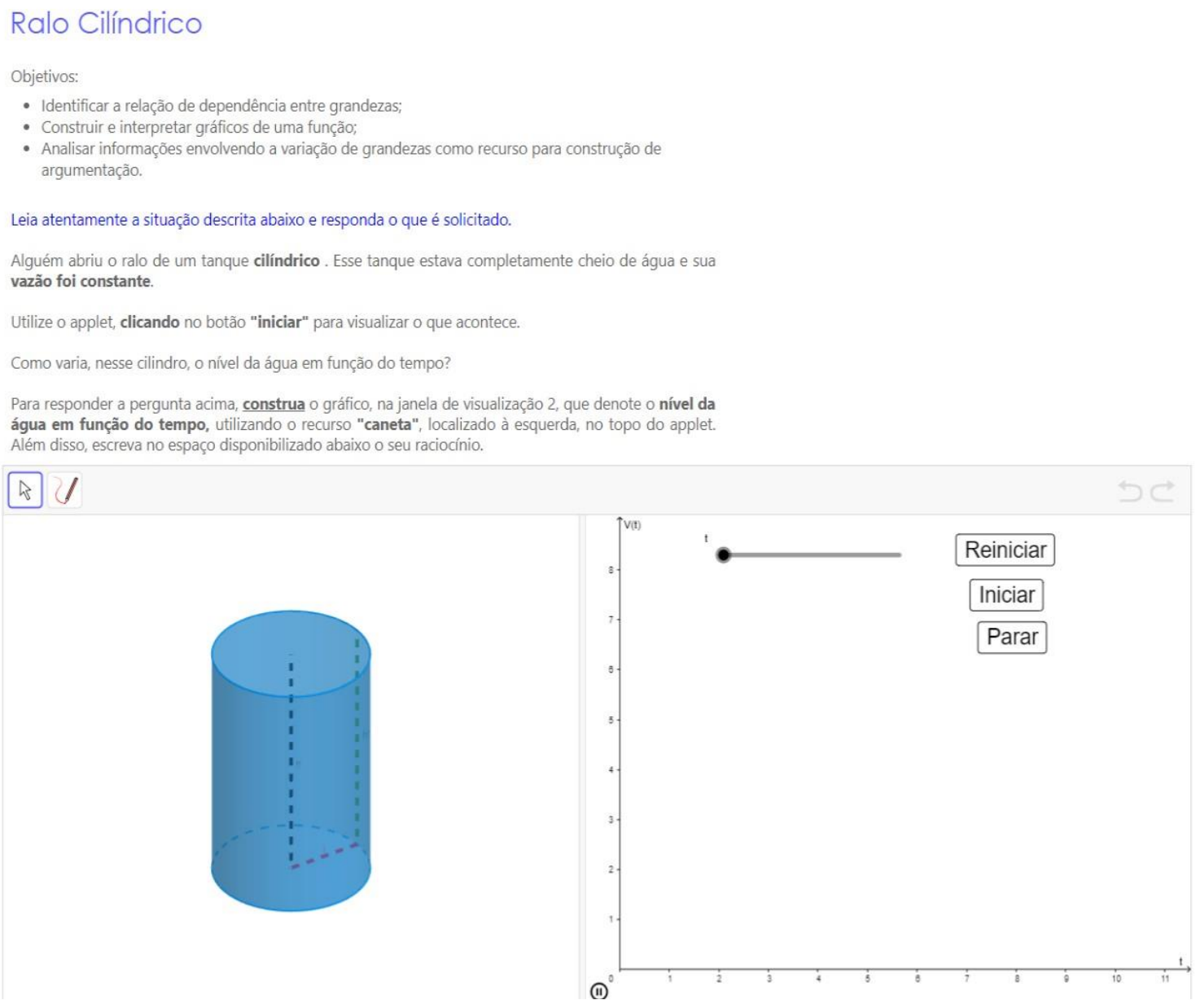

Escreva, detalhadamente, teu raciocínio para construção do gráfico. (Esse é o momento em que você poderá convencer-me a concordar ou não com a construção do teu gráfico; por isso, lembre-se de escrever bons argumentos).

$$
\underline{A}
$$

$f_{x}$

Fonte: Acervo dos Autores, 2020. 
Figura 4: Elementos $A, B, C, D, E, F$ que compõe o objeto de aprendizagem $R C$

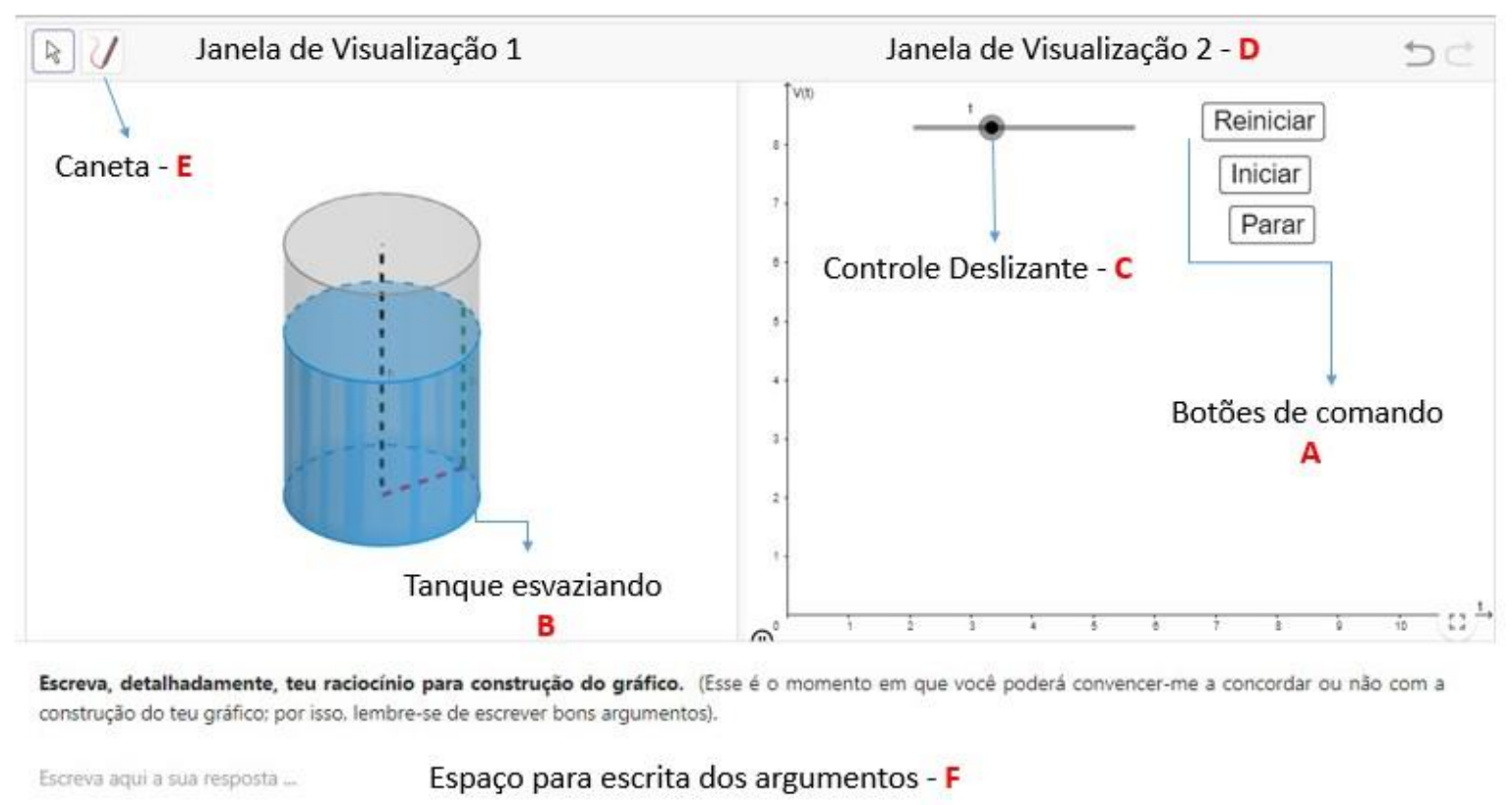

Fonte: Acervo dos Autores, 2020.

Participaram da atividade 27 alunos, já que um havia faltado. Ao realizá-la, alguns estudantes perguntaram como poderiam recomeçar o gráfico, pois o GeoGebra não oferece o ícone "Borracha". Nesse momento, o professor explicou que bastava clicar sobre a construção e deletar o que estava feito até o momento. Ao findar a aula, o professor verificou que todos enviaram a atividade e os informou que durante a semana, de maneira assíncrona, eles receberiam o feedback sobre as construções realizadas.

Durante a semana, o professor realizou as correções da atividade e disponibilizou o feedback. Aqueles que não haviam respondido de forma satisfatória a atividade inicial tiveram uma nova oportunidade de aprendizagem, pois puderam refletir sobre as considerações feitas pelo professor e, então, revisar suas resoluções. Vale informar que os alunos que refizeram a tarefa, realizaram as representações da função em seus respectivos cadernos de aula e encaminharam pelo post uma imagem destas.

$\mathrm{Na}$ quarta aula, outra vez de forma síncrona, o professor iniciou convidando os alunos a socializarem o raciocínio e os argumentos referentes à representação da situação-problema RC no registro gráfico. Após a discussão entre os alunos mediada pelo professor, foi feita a correção com a utilização de uma mesa digitalizadora, a qual possibilitou ao professor escrever e desenhar. A plataforma Webex permitiu o compartilhamento de tela, enquanto $o$ professor explicava e desenhava, conforme Figura 5. Em tempo real, os alunos acompanharam as explicações e puderam sanar as dúvidas que ainda existiam.

Terminada a correção, o professor liberou aos alunos a quarta atividade, denominada "Ampulheta $(\mathbf{A})$ "15, informando-Ihes que teriam até o final da aula para entregá-la.

Nesta atividade (A), conforme layout na Figura 6, foi proposta a solução de uma situação-problema que apresentava uma ampulheta, formada por três figuras de mesma

\footnotetext{
${ }^{15}$ Disponível em: <https://www.geogebra.org/m/unepfn48 >. Acesso em: 28 de ago. de 2021.
} 
altura (dois troncos de cone iguais e um cilindro). A situação em si informava que essa ampulheta estava completamente vazia e no topo dela se abriria uma torneira com vazão constante.

Figura 5: Compartilhamento da tela do professor na correção da atividade RC realizada conjuntamente com os alunos

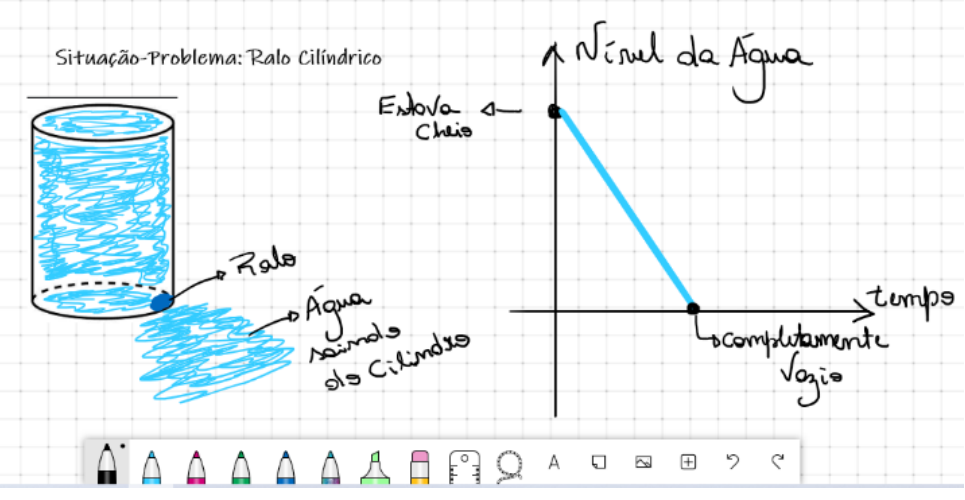

Fonte: Acervo dos Autores, 2020.

Figura 6: Layout do objeto de aprendizagem Ampulheta no GeoGebra e os elementos que a compõem Objetivos:

- Identificar a relação de dependència entre grandezas:

- Construir e interpretar gráficos de uma funçăo

- Analisar informaçōes envolvendo a variação de grandezas como recurso para construção de argumentaçăo.

Leia atentamente a situação descrita abaixo e responda o que é solicitado.

(ENEM. 2014 - ADAPTADA) Para comemorar o aniversário de uma cidade, um artista projetou uma escultura transparente e oca, cujo formato foi inspirado em uma ampulheta. Ela é formada por três partes de mesma altura: duas sẫo troncos de cone iguais e a outra é um cilindro. A vista frontal dessa escultura está representada no applet abaixo.

No topo da escultura foi ligada uma torneira que verte água, para dentro dela. com vazão constante.

Utilize o applet, clicando no botào "iniciar" para visualizar o que acontece.

Como varia, nessa ampulheta, o nivel da água em funçăo do tempo?

Para responder a pergunta acima, construa o gráfico, na janela de visualização 2, que denote $\circ$ nível da água em função do tempo, utilizando o recurso "caneta". localizado à esquerda no topo do applet.

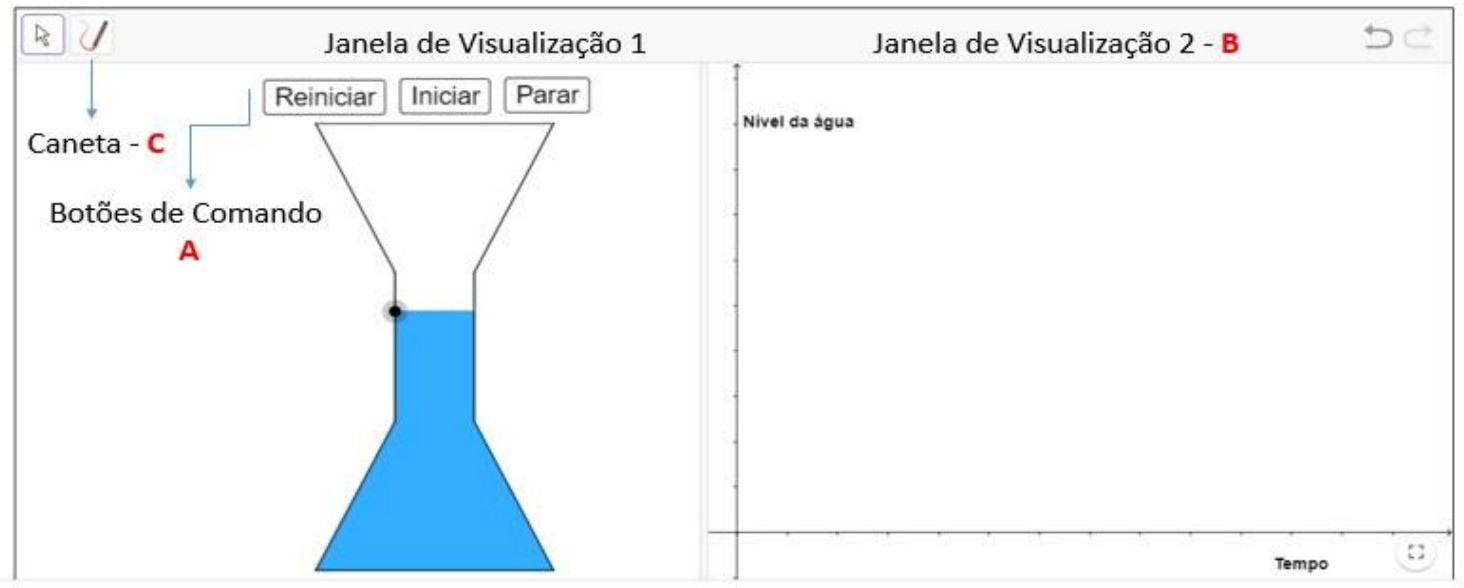

Nesse espaço, explique detalhadamente seu raciocínio.

Escreva aqui a sua resposta -- Espaço para escrita dos argumentos - D

Fonte: Acervo dos Autores, 2020. 
Para representar essa ação, adaptada do ENEM (2014), construímos um applet que permitiu a visualização desta cena de maneira dinâmica, ou seja, a ampulheta sendo completada por água. Para isso, os alunos foram convidados a clicar no botão de comando iniciar (Figura $6-\mathrm{A}$ ), etapa em que eles puderam observar o nível da água subindo com o decorrer do tempo. Passada esta etapa, foi solicitado que construíssem o gráfico que representou o comportamento do nível da água em função do tempo na "janela de visualização 2" (Figura 6-B), com o recurso "Caneta" (Figura $6-$ C). Além disso, eles precisaram justificar, em linguagem natural, a construção dos seus gráficos no espaço destinado abaixo das janelas de visualização (Figura $6-D$ ).

Nesta atividade, estavam presentes 27 alunos e nenhum deles solicitou ajuda do professor. Ao final da aula, o professor verificou que todos haviam entregado a atividade. Então, ao encerrar, os alunos foram informados de que, durante a semana, de maneira assíncrona, mais uma vez receberiam o feedback sobre as construções realizadas.

\section{Discussão dos resultados}

As atividades propostas foram utilizadas para introduzir o conceito de função, tendo em vista que esse grupo de alunos não havia estudado formalmente esse conteúdo e tampouco realizado atividades com foco no desenvolvimento do raciocínio covariacional. A tecnologia do GeoGebra possibilitou explorar esse conceito por meio de diferentes representações da situação-problema, tais como a visualização e linguagem natural utilizada pelos alunos em seus argumentos para justificar as escolhas e construções realizadas. Com isso, foi possível analisar a compreensão de função dos alunos acerca de situações dinâmicas que envolveram duas quantidades que mudavam simultaneamente.

A familiarização dos alunos com a ferramenta Grupos aconteceu de forma relativamente simples. Quando o professor, na aula síncrona, compartilhou a tela do seu notebook e apresentou o seu funcionamento, houve poucas dúvidas quanto a sua utilização. A facilidade de manuseio que o GeoGebra oferece pode ter motivado os alunos a participarem ativamente das aulas assíncronas, aproximando professor e alunos nesse processo de ensino e aprendizagem remoto.

Durante as correções realizadas pelo professor, de forma assíncrona, foi possível perceber que a maior dificuldade dos alunos estava em justificar suas escolhas na linguagem natural, sobre suas representações das funções no registro gráfico. É possível que essa dificuldade se deva ao fato de as atividades requererem a transição entre as representações da função nos diferentes registros. O feedback dado pelo professor propiciou oportunidades de aprendizagem, encorajando os alunos a pensarem em outras hipóteses, a irem além das conjecturas iniciais.

Para análise dos resultados obtidos, levamos em consideração o marco teórico proposto por Carlson et al. (2002), sintetizado no Quadro 1. Tivemos um olhar atento no que diz respeito aos alunos reconhecerem as variáveis envolvidas numa situação-problema e como elas variam simultaneamente em uma relação de dependência (AM1). Para AM2, a atenção ficou destinada a coordenação de como as variáveis se comportam, uma em relação à outra (por exemplo, aumentando, diminuindo). O foco para AM3 foi para a coordenação da quantidade de variação de uma variável enquanto imagina a variação na outra quantidade (por exemplo, para cada copo de água adicionado a um recipiente, o nível de água neste 
recipiente sobe cada vez mais). Já para AM4, concentramo-nos na taxa de variação da saída em relação à entrada para incrementos constantes da entrada. E por fim, a AM5 é revelada pela construção de uma curva que inclui a compreensão de ponto de inflexão que envolve a mudança de concavidade de uma função, a saber, local em que a taxa de variação muda de crescente para decrescente, ou de decrescente para crescente.

$\mathrm{Na}$ atividade Cone Invertido (Cl), dos 28 alunos participantes, 13 selecionaram corretamente o gráfico que representava a situação-problema, ou seja, marcaram a resposta de letra (c). Entretanto, 15 não responderam satisfatoriamente. O Quadro 3 apresenta as alternativas e o número de recorrência das escolhas em cada uma delas.

Quadro 3: Alternativas e o número de escolhas na atividade Cone Invertido

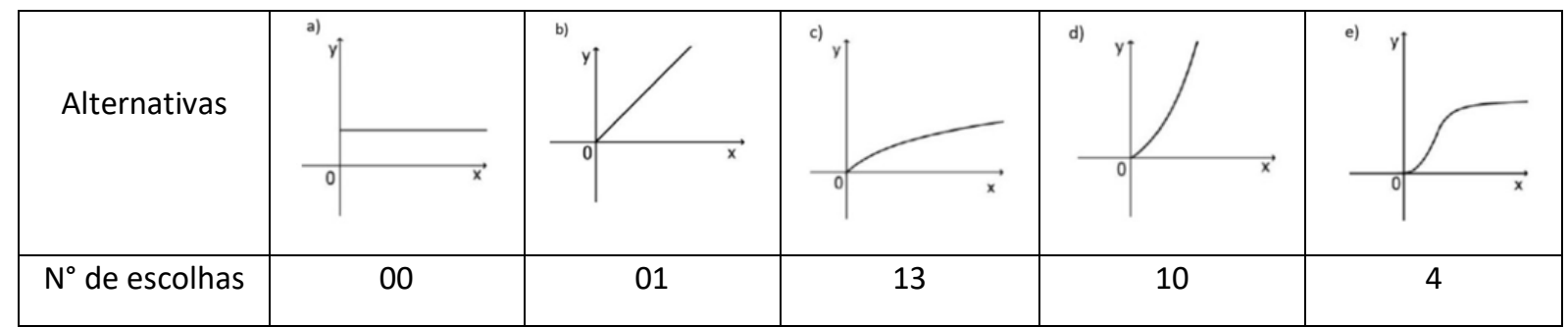

Fonte: Dados dos autores, 2020.

Foi possível perceber, por meio da análise dos registros, que todos os 15 alunos, que não identificaram corretamente o comportamento gráfico da situação abordada, reconheceram que à medida que o tempo passava a altura (nível de água no cone) ia aumentando. Entretanto, estes alunos não souberam interpretar com que rapidez acontecia esse crescimento, ou seja, era necessário levar em consideração que a taxa de variação do nível da água em função do tempo iria diminuir, devido o formato do cone invertido, pois o raio vai aumentando. Por isso, consideramos que nesta atividade esses 15 alunos se envolveram em AM1 e AM2, reconhecendo as variáveis envolvidas na situação e a direção do gráfico.

A Figura 7 apresenta a resolução do aluno A2 que inicialmente não respondeu satisfatoriamente. Porém, após termos fornecido o feedback do professor, o aluno retornou com sua nova conclusão, desta vez, satisfatória. Analisando o retorno do aluno, percebemos que inicialmente ele reconhece que as variáveis mudam simultaneamente e identifica a direção dessa variação, com o comportamento de um gráfico crescente (AM1, AM2), mas não consegue aplicar uma AM3 devido à possível incompreensão sobre a quantidade de variação dessa mudança. Após feedback do professor, o fazendo refletir sobre sua primeira resolução, ele provavelmente consegue aplicar uma AM3. Essa possibilidade do feedback num ambiente virtual, fornecida pelo GeoGebra Grupos, mostra a importância da comunicação entre professor e aluno para estimular a aprendizagem. 
Figura 7: Resposta do aluno A2 enviada ao professor e feedback

Qual dos gráficos foi escolhido? Justifique. (A justificativa é o momento em que você poderá convencer-me a concordar ou não com tua escolha; por isso, lembre-se de escrever bons argumentos).

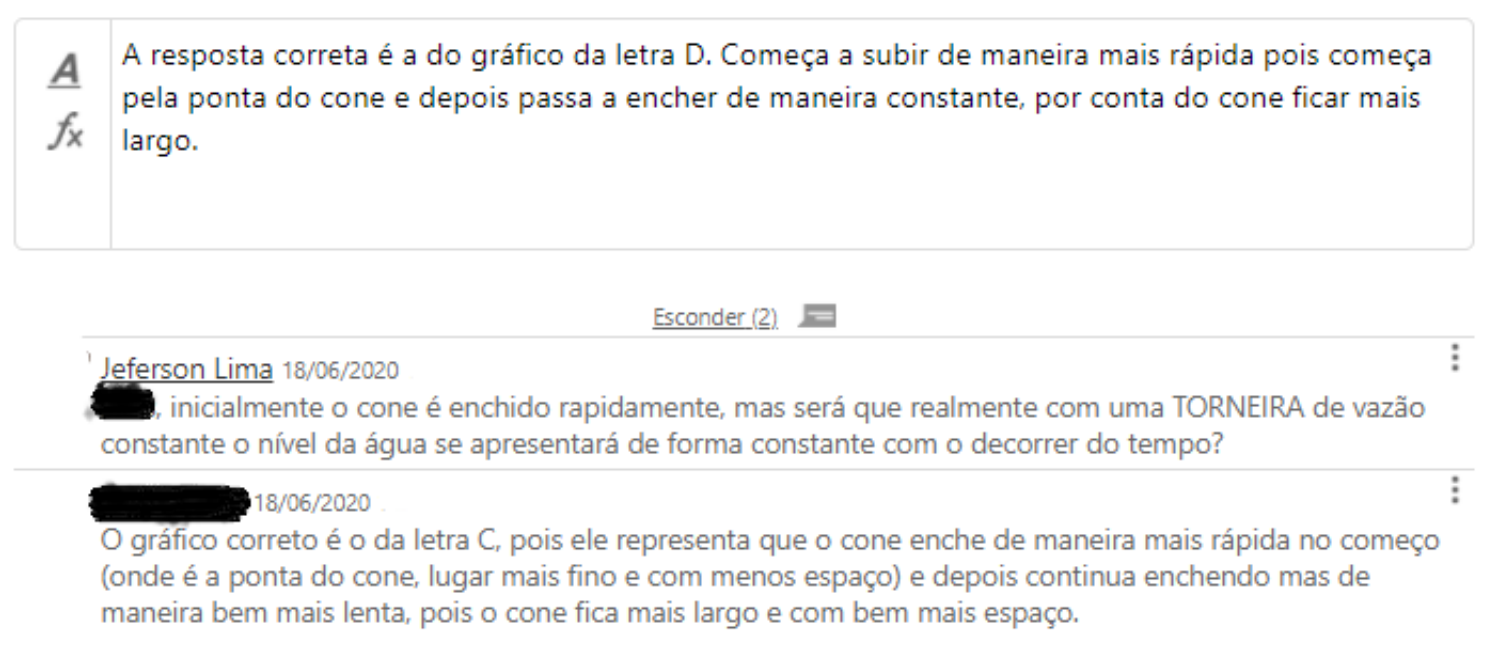

Fonte: Acervo dos Autores, 2020.

Dos 13 alunos que identificaram a resposta correta, letra (c), 05 não justificaram adequadamente em linguagem natural. A Figura 8 mostra um exemplo deste fato, pois o aluno A3 só identificou a direção e não a quantidade de variação. Assim, pela justificativa apresentada, os gráficos $b, d$ e e, poderiam ser escolhidos. Logo, enquanto 08 alunos dos 13 acertaram a escolha do gráfico e justificaram apropriadamente a escolha, os outros 05 somente identificaram a direção de variação (AM2).

Figura 8: Identificação correta do gráfico com justificativa insatisfatória apresentada pelo aluno A3

Qual dos gráficos foi escolhido? Justifique. (A justificativa é o momento em que você poderá convencer-me a concordar ou não com tua escolha; por isso, lembre-se de escrever bons argumentos).

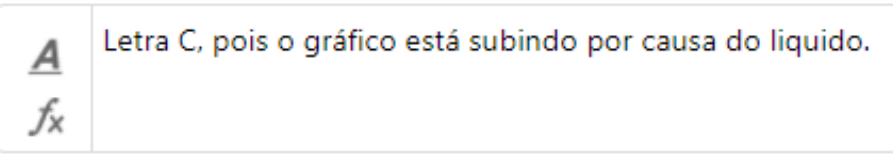

Fonte: Acervo dos Autores, 2020.

O Quadro 4 apresenta as alternativas da situação-problema e o número de recorrências das escolhas em cada uma delas pelos alunos na atividade Clube do Livro (CL). Nesta atividade, 16 alunos identificaram corretamente o gráfico correspondente, letra (b), e justificaram adequadamente. Na justificativa apresentada pelo aluno A4, (Figura 9), mesmo não tendo familiaridade com a palavra "exponencial" e sua definição formal, ele recorreu, em sua justificativa, à expressão "curva para cima mostrando o quão rápido ele leu", provavelmente para se referir a concavidade do gráfico (AM5). 
Quadro 4: Alternativas e o número de escolhas na atividade $\mathrm{CL}$

\begin{tabular}{|l|c|c|c|c|c|}
\hline Alternativas & & & & & \\
\hline $\mathrm{N}^{\circ}$ de escolhas & 08 & 16 & 03 & 01 & 0 \\
\hline
\end{tabular}

Fonte: Dados dos autores, 2020.

Figura 9: Justificativa da escolha do gráfico apresentada pelo aluno $\mathrm{A} 4$ na atividade $\mathrm{CL}$

Qual dos gráficos foi escolhido? Justifique. (A justificativa é o momento em que você poderá convencer-me a concordar ou não com tua escolha; por isso, lembre-se de escrever bons argumentos).

\footnotetext{
A O gráfico escolhido seria $\circ \mathrm{b}$, pois o leitor disse acima que a cada página que ele lia mais rápido ele quer terminar esse livro e o único gráfico que mostra com uma curva para cima mostrando o

$f_{x}$ quão rápido ele leu esse livro seria o da letra "b".
}

Fonte: Acervo dos Autores, 2020.

Os outros 12 alunos não reconheceram o gráfico correto. A Figura 10 evidencia a justificativa do aluno A5 que selecionou a opção "a", não conseguindo se envolver na AM4, pois na representação gráfica selecionada, a reta nos diz que o número de páginas lidas aumenta em função do tempo, porém, a variação do número de página em função do tempo é sempre constante, o que não corresponde ao problema proposto.

Figura 10: Justificativa apresentada pelo aluno A5 que identificou a função linear como representação gráfica da atividade $\mathrm{CL}$

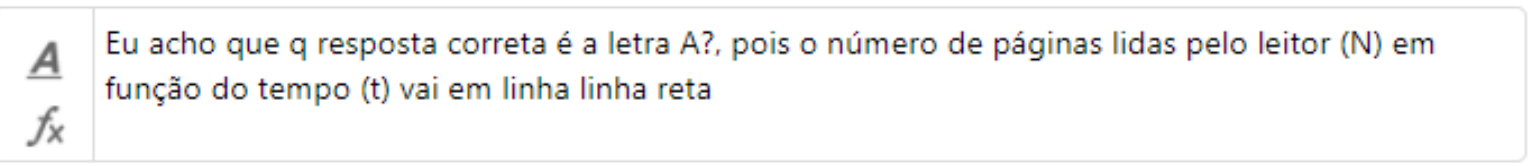

Fonte: Acervo dos Autores, 2020.

A atividade Ralo Cilíndrico (RC) foi realizada após a discussão entre os alunos e correção do professor das atividades $\mathbf{C l}$ e $\mathbf{C L}$ em uma aula síncrona. Consideramos esse procedimento fundamental para melhor compreensão da proposta, visto que, foi exigida do aluno, além da compreensão da situação-problema, a representação gráfica e sua justificativa em linguagem natural.

Dos 27 estudantes, apenas 10 construíram e justificaram seu gráfico corretamente. Os demais resultados podem ser dividos nas seguintes categorias: contrução de uma reta crescente (12 respostas), que demonstra a compreensão da variação entre o nível da água e o tempo, mas não a direção correta; construção de uma reta constante (01 resposta) e de uma curva (03 respostas), que demonstra a não identificação correta da variação e da direção; não realização da tarefa (01 resposta). 
Na Figura 11, observamos que o aluno A6 executou AM1 e AM2, pois em sua justificativa na representação da linguagem natural, ele demonstra que identificou uma relação entre o nível da água e o tempo: "diminuindo o nível da água em função do tempo". Esse registro do aluno não corresponde à sua representação gráfica. Duval (2012) esclarece essa dificuldade dos alunos reconhecerem e converterem o mesmo objeto matemático em suas diferentes representações e afirma que "pode-se observar, em todos os níveis de ensino, na grande maioria dos alunos, um isolamento de registros de representação. Estes não reconhecem o mesmo objeto nas representações que são dadas em sistemas semióticos diferentes" (DUVAL, 2012, p.283). Dessa forma, é provável que este aluno tenha observado que o nível da água estava diminuindo em função do tempo, mas não soube representar graficamente essa situação, pois ele iniciou o gráfico no tempo zero, como se o cilindro estivesse vazio e depois passou a encher, contrariando sua resposta em linguagem natural. Este aluno, portanto, não conseguiu transitar entre os dois registros de representação.

Após o feedback do professor, Figura 12, o aluno A6 refez a atividade no seu caderno devolvendo um post (Figura 12), a foto com a nova justificativa e a nova representação gráfica, obtendo progresso. Possivelmente após o feedback, o raciocínio executado inicialmente, uma AM1, se envolveu nas ações AM2 e AM3, pois o aluno corrigiu a representação gráfica (reta decrescente), e a sua justificativa ("o tanque se esvazia constantemente à medida que o tempo passa"), transitando nas duas representações (natural e gráfica) do mesmo objeto matemático.

Figura 11: Resposta do aluno A6 que não relacionou a linguagem natural à sua representação gráfica
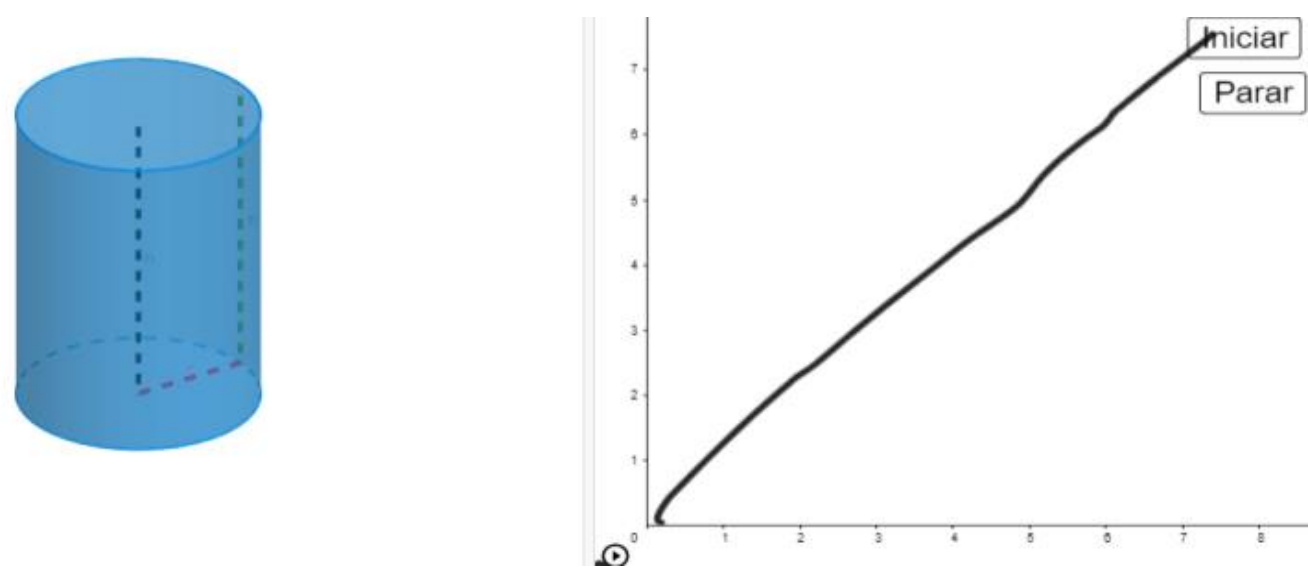

Escreva, detalhadamente, teu raciocínio para construção do gráfico. (Esse é o momento em que você poderá convencer-me a concordar ou não com a construção do teu gráfico; por isso, lembre-se de escrever bons argumentos).

A Meu raciocínio foi que como temos um cilindro e a vazão é constante, então o gráfico deve ser reto na diagonal, pois ele não parou em nenhum momento nem mudou o fluxo, seguiu

$f_{x}$ constantemente, diminuindo o nível da água em função do tempo.

Fonte: Acervo dos Autores, 2020.

Fica evidente, nesse contexto, a importância de o professor analisar as respostas dos alunos e propiciar feedback, oportunizando novas aprendizagens. Porém, percebemos que o 
professor, no feedback dado, poderia ter expressado mais questionamentos ao aluno sobre suas representações iniciais. Perguntas como: "Qual o nível da água no tempo inicial?"; "E no tempo final?"; "O nível da água está aumentando/diminuindo?"; "Como diminui/aumenta?", explorariam mais o raciocínio covariacional do aluno para responder aos questionamentos. Esta é, portanto, uma prática que pode ser mais bem exercitada pelo professor: perguntas no lugar de respostas.

Figura 12: Feedback do professor e devolutiva do aluno A6

\section{Jeferson Lima 9 de Junho de 2020 15:04}

da forma que você representou o tempo inicial relacionado com o nível inicial, fica representado que inicialmente não tinha água e ao longo do tempo o cilindro foi enchendo. Será que se tua reta estivesse em outra posição você conseguiria representar essa vazão constante?

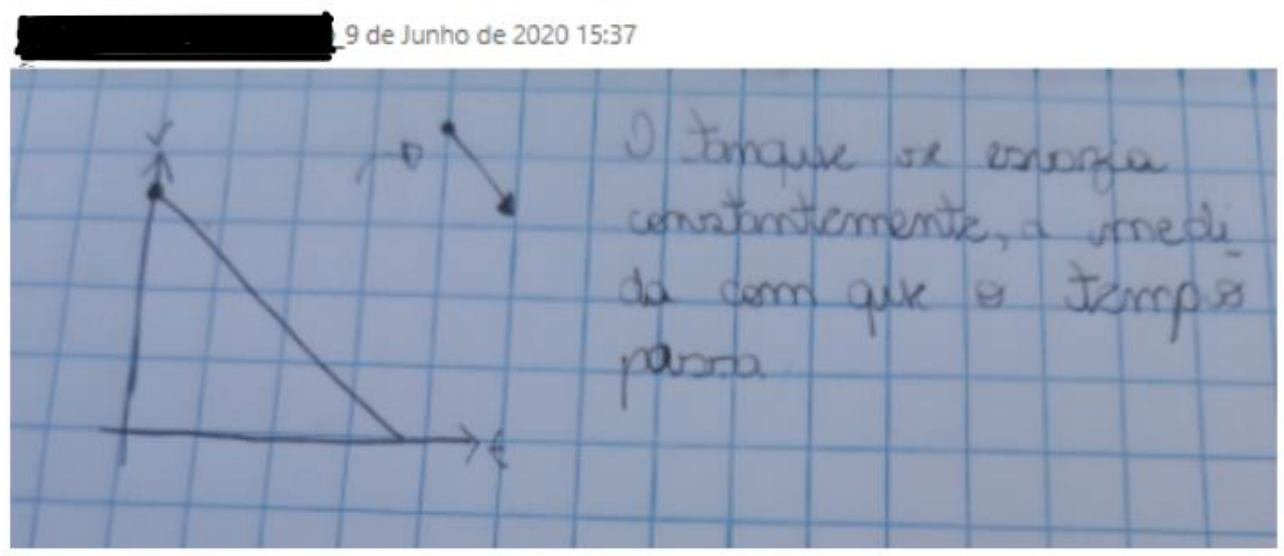

Fonte: Acervo dos Autores, 2020.

Na análise da atividade Ampulheta, verificou-se que, dos 27 participantes, apenas 07 conseguiram representar o gráfico e justificar adequadamente. Os alunos que obtiveram resoluções satisfatórias, em suas justificativas, explicaram que o gráfico era representado por três períodos com variações diferentes. Um exemplo disso é a reposta do aluno A7, que, mesmo em uma linguagem natural, percebe esses três períodos: "Começa no ponto 0 bem devagar, enchendo cada vez mais rapidamente até a parte estreita (meio), depois que sai dessa parte estreita demora mais tempo para encher todo o restante". Consideramos que esses alunos executaram uma AM3, pois souberam representar adequadamente 0 comportamento crescente do gráfico e a quantidade de mudança.

Já dos 20 alunos que não responderam adequadamente, selecionamos duas resoluções, dos alunos A8 e A9, para apresentar o nível de raciocínio covariacional executado por eles.

Na resolução apresentada pelo aluno A8, (Figura 13), foi possível perceber que ele identificou uma relação entre o nível da água e o tempo nos troncos de cone, descrevendo-a em linguagem natural e representando essa relação no registro gráfico, se envolvendo numa AM1, AM2 e AM3. Entretanto, na parte do cilindro, ele não percebe a variação do nível da água, tanto nos registros de linguagem natural, como no gráfico, ele representa o nível da água mantendo-se constante com o passar do tempo. Isso nos revela que esse aluno foi capaz de imaginar uma mudança quando a água chegou ao cilindro, mas não conseguiu considerar que a reta seria crescente, já que o nível da água continua aumentando no recipiente. 
Figura 13: Representações da relação entre o nível da água e o tempo na ampulheta apresentada pelo aluno A8

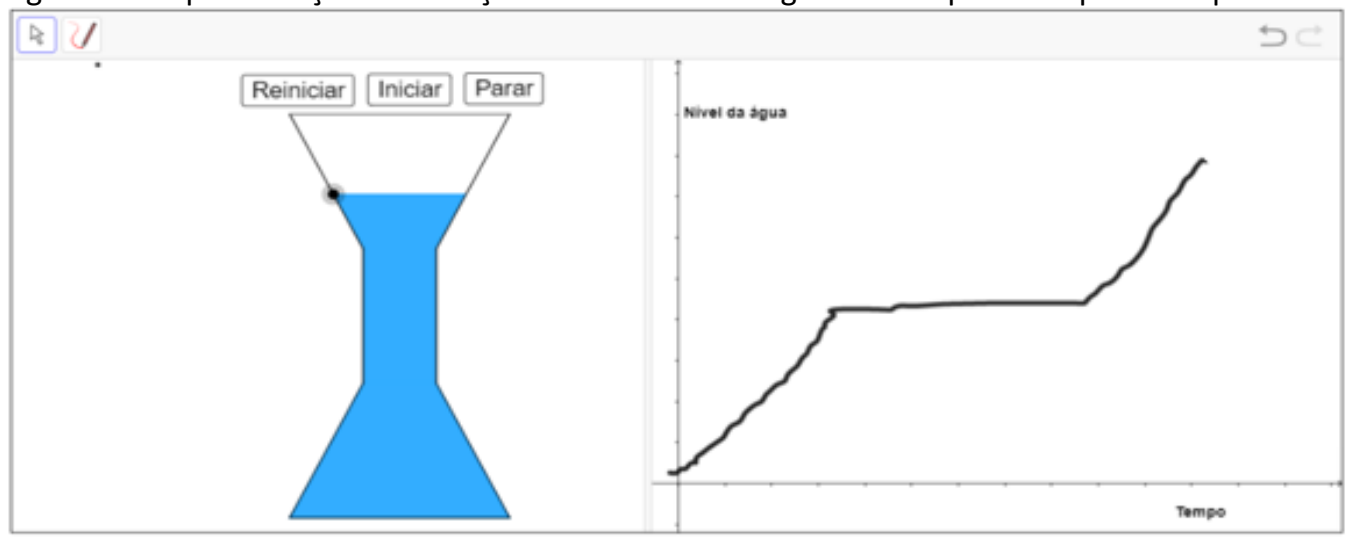

Nesse espaço, explique detalhadamente seu raciocínio.

A O nível da água vai aumentando até chegar ao cilindro. A partir daí de forma constante a água
$f_{x}$ enche até chegar ao tronco de cone e continua subindo até que seja completamente enchido.

Fonte: Acervo dos autores, 2020.

No raciocínio expresso pelo aluno A9, na Figura 14, foi possível perceber que ele identificou as variáveis envolvidas e que o nível da água aumentava em relação ao tempo, se envolvendo nas AM1 e AM2. Porém, não identificou como ocorreria esse aumento, tanto em linguagem natural quanto na representação gráfica. Ou seja, pelo raciocínio covariacional pouco desenvolvido, ele não levou em consideração que as distinções que a ampulheta apresenta em seu formato impacta na variação do nível da água em função do tempo, ocasionando uma mudança no comportamento da representação gráfica.

Figura 14: Representações da relação entre o nível da água e o tempo na ampulheta apresentada pelo aluno A9

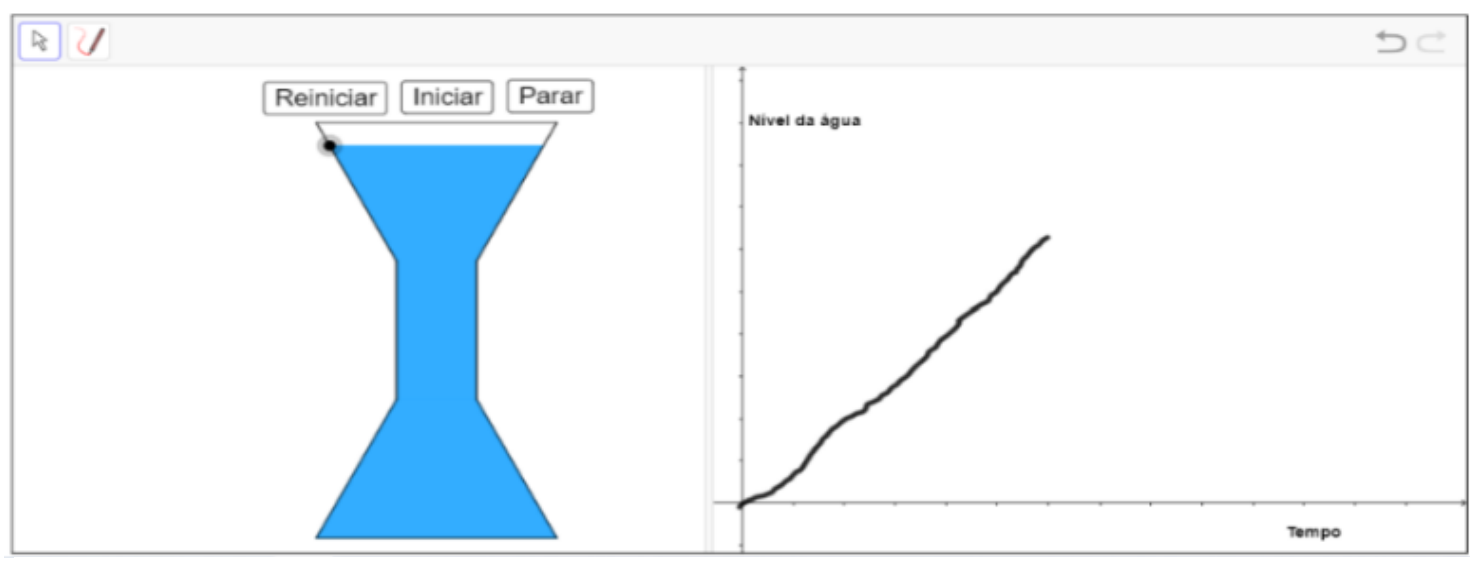

Nesse espaço, explique detalhadamente seu raciocínio.

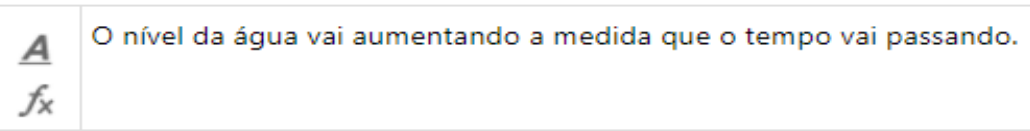

Fonte: Acervo dos autores, 2020. 
As representações da função que descreve o comportamento do nível da água em função do tempo, nos registros gráfico e língua natural (Figuras 13 e 14), apresentadas pelos dois alunos (A8 e A9) revelam fragilidades no raciocínio covariacional e sinalizam que a mobilização entre AM3, AM4 e AM5 não é trivial para os alunos, conforme evidenciado nas pesquisas de Carlson e Thompson (2005).

\section{Considerações finais}

O objetivo deste relato foi apresentar a experiência de transição das aulas presenciais para remotas vivenciada por um professor de matemática do Ensino Médio que, durante esse período, precisou adaptar recursos digitais que já se faziam presentes em sua prática e incorporar novas ferramentas.

A formação deste professor, que teve previamente a oportunidade de pesquisar sobre tecnologias digitais, foi um dos fatores de extrema importância nesse período. Os conhecimentos adquiridos e a familiaridade com as tecnologias possibilitaram uma adaptação menos abrupta das atividades presenciais para o remoto. Sem essa formação, certamente o professor encontraria dificuldades em adaptar o ensino de funções do ambiente papel, quadro e giz para os meios digitais. Naturalmente isso demanda tempo extra do professor para planejamento, pesquisa, adaptação de atividades ao ambiente digital, fornecimento de feedback individualizado, além da necessidade de um equipamento tecnológico adequado, como a mesa digitalizadora utilizada para as aulas.

Contar com as ferramentas do GeoGebra para ensinar funções na perspectiva da covariação potencializou a construção de atividades com foco no raciocínio covariacional e viabilizou ambientes para que o aluno expressasse seu raciocínio por meio de diferentes registros de representação, já que para o desenvolvimento cognitivo relativo à compreensão em matemática, a conversão de um segundo registro de representação se faz necessário, além de que "é essencial, na atividade matemática, poder mobilizar muitos registros de representação semiótica (figuras, gráficos, escrituras simbólicas, língua natural, etc...) no decorrer de um mesmo passo, poder escolher um registro no lugar de outro" (DUVAL, 2012, p.270).

Outro ponto importante a considerar foi a dificuldade de os alunos reconhecerem a covariação existente nas atividades propostas e representarem em linguagem natural ou gráfica seus argumentos relativos ao raciocínio covariacional. Observamos nas resoluções das atividades que vários alunos empregaram apenas as ações AM1 e AM2 e raramente se moveram com flexibilidade entre as demais ações, indo ao encontro dos resultados apresentados por Carlson e Thompson (2005). Entretanto, corroboramos com esses autores, quando eles nos informam que "o raciocínio covariacional é desenvolvido", (THOMPSON E CARLSON, 2017, p. 426, tradução nossa), logo cabe a nós, professores, expandirmos atividades e discussões que possibilitem o desenvolvimento desse raciocínio.

Em se tratando de discussões, as aulas síncronas e assíncronas proporcionaram ao professor e aos alunos momentos distintos e necessários para esse desenvolvimento, pois enquanto as aulas síncronas, mediadas pelo professor, incentivaram os alunos ao compartilhamento de ideias, com o grande grupo, relativas às soluções dos problemas, as aulas assíncronas estimularam nos alunos, além de reflexões acerca das argumentações e representações iniciais, uma oportunidade do desenvolvimento do raciocínio covariacional a partir do feedback dado pelo professor. 
Encerramos salientando a importância da formação do professor de matemática, tanto para oferecer oportunidades de os alunos explorarem o raciocínio covariacional, que é um "raciocínio matemático imprescindível para os alunos compreenderem conceitos-chave da matemática" (JOHNSON et al., 2018, p.1224, tradução nossa), como para utilização de recursos tecnológicos.

\section{Referências}

CARLSON, Marilyn P. Physical enactment: a powerful representational tool for understanding the nature of covarying relationships. Representations and mathematics visualization, p. 63-77, 2002.

CARLSON, Marilyn P.; JACOBS, Sally; COE, Edward; LAERSEN, Sean; HSU, Eric. Applying covariational reasoning while modeling dynamic events: A framework and a study. Journal for research in mathematics education, v. 33, n. 5, p. 352-378, 2002.

CARLSON, Marilyn P.; THOMPSON, Patrick W. The Reflective Relationship Between Individual Cognition and Classroom Practice: a Covariation Framework and Problem Solving Research Inform Calculus Instruction. In: Makalah disajikan dalam Annual Meeting of the American Educational Research Association, Montreal, Quebee. 2005.

DUVAL, Raymond; MORETTI, Trad Méricles Thadeu. Registros de representação semiótica e funcionamento cognitivo do pensamento Registres de représentation sémiotique et fonctionnement cognitif de la pensée. Revemat: Revista Eletrônica de Educação Matemática, v. 7, n. 2, p. 266-297, 2012.

JOHNSON, Heather L.; MCCLINTOCK Evan D.; KALIR, Jeremiah; OLSON, Gary. Networking theories to design dynamic covariation techtivities for college algebra students. In: Proceedings of the 21st Annual Conference on Research in Undergraduate Mathematics Education. 2018.

LIMA, Jeferson Moizés. Covariação e o conceito de função: objetos dinâmicos. Produto Educacional (Mestrado em Ensino de Ciências, Matemática e Tecnologias) - Universidade do Estado de Santa Catarina. Joinville, p. 42. 2019a.

LIMA, Jeferson Moizés. Objetos dinâmicos de aprendizagem para exploração do conceito de função na perspectiva da covariação. Dissertação (Mestrado em Ensino de Ciências, Matemática e Tecnologias) - Universidade do Estado de Santa Catarina. Joinville, p. 101. 2019b.

MOORE, Kevin C.; THOMPSON, Patrick W. Shape thinking and students' graphing activity. In: proceedings of the 18th meeting of the MAA special interest group on research in undergraduate mathematics education. Pittsburgh, PA: RUME, p. 782-789, 2015.

THOMPSON, Patrick W.; CARLSON, Marilyn P. Variation, covariation, and functions: Foundational ways of thinking mathematically. In J. Cai (Ed.), Compendium for research in mathematics education. Reston, VA: National Council of Teachers of Mathematics, p. 421-456, 2017. 